\title{
AS RAZÕES DA GUERRA CIVIL: NECESSIDADE, CRENÇA E GANÂNCIA
}

\author{
Gabriel Cepaluni
}

\author{
Filipe Mendonça
}

Quais as causas da guerra? Esta é uma questão clássica das relações internacionais. O final da guerra fria trouxe consigo uma nova ordem internacional. Com ela, tornaram-se necessárias readequações teóricas profundas para compreender as novas dinâmicas globais.

Os "novos conflitos" são bastante diferentes dos tradicionais. Na verdade, argumenta-se que os "antigos conflitos" entre Estados soberanos são improváveis por pelo menos três motivos. Primeiro, a invenção de armas nucleares tornou-os irracionais. Uma pequena quantidade de armamento nuclear poderia destruir nações inteiras e prejudicar grande parte do planeta por causa dos efeitos da radiação. Em segundo lugar, o amplo acesso à informação no Ocidente tornou mais difícil a ascensão de líderes como Hitler e Mussolini, capazes de mobilizar todo um país em prol de anseios expansionistas. Por último, não há mais os grandes contenciosos econômicos capazes de provocar guerras entre Estados. As instituições internacionais e seus fóruns de solução de controvérsias criaram mecanismos para solução de conflitos por meio da diplomacia, da negociação, sendo desnecessário, por exemplo, o lançamento de mísseis para reduzir taxas de importação.

Dentro desse novo cenário, o principal objetivo do livro Rethinking the Economics of War: The Intersection of Need, Creed, and Greed é refletir sobre as razões dos conflitos civis que sobreviveram à guerra fria. Nesse sentido, três termos são amplamente utilizados pelos autores da coletânea: "necessidade", "crença" e "ganância". A "necessidade" origina-se do sentimento de injustiça causado pela repressão política e pela privação econômica. A “crença" pode significar a fé "cega” ou um sentimento de identidade de um grupo. Já a "ganância" refere-se ao desejo de se apropriar de recursos públicos. Assim, a discriminação baseada nas crenças e nos sentimentos de identidade junta-se às ambições pessoais ou grupais de ganhos particulares (a "ganância”) para produzir conflitos com múltiplos motivos coletivos e privados.

Contrariando as previsões mais otimistas, o fim da guerra fria e o término da influência das superpotências nos assuntos domésticos de países do Terceiro Mundo não provocaram uma diminuição do número de guerras civis. Certamente, alguns conflitos armados ocorriam fortemente influenciados pela lógica da guerra fria: as guerras do Camboja, de El Salvador, da Guatemala e de Moçambique são exemplos disso. Contudo, os conflitos no Afeganistão, em Angola, na Somália e no Congo só podem ser entendidos se buscarmos explicações que não estavam presentes até então.

Assim, se os conflitos civis da época da guerra fria aconteciam basicamente por motivos políticos e ideológicos, os "novos conflitos" ocorrem pelas mais diversas razões, entre elas, disputas por territórios, recursos naturais, pressão demográfica, mas também por questões religiosas, ideológicas e culturais.

A obra Rethinking the Economics of War tem uma estrutura bastante comum entre os livros da área de Relações Internacionais. O primeiro capítulo introduz o leitor no debate sobre os determinantes econômicos das "modernas" guerras civis, mostrando que as variáveis "sociais" e "políticas" ainda servem para explicar as razões dos conflitos armados. Do segundo ao oitavo capítulo, apresentam-se estudos de casos que dão base empírica às proposições desenvolvidas nos capítulos posteriores, sendo que o penúltimo (o nono) tem pretensões práticas e o último (o décimo) fornece explicações teóricas. Enfatiza-se que as conclusões dos dois últimos capítulos são meramente "propositivas", não fornecem a chave para todos os problemas do mundo nem procuram testar uma teoria aplicada a todas as guerras civis, mas, sim, contestam modelos e soluções “simplistas" (p. 260-261).

No primeiro capítulo, Cynthia J. Arnson resume o debate sobre as causas das guerras civis, tentando mostrar a diferença entre as "guerras tradicionais" e as "novas guerras" (p. 2). Como aponta a autora, apesar 
de não ser um fenômeno propriamente recente, as chamadas "novas guerras" não eram consideradas problemas estruturais para a comunidade internacional. Tais guerras caracterizam-se pelo fim da divisão entre o crime organizado e a guerra propriamente dita. Esse tipo de conflito é localizado, atinge principalmente civis e depende de conexões transnacionais para sua manutenção. Além disso, cria uma economia paralela baseada em saques e transações no mercado negro.

Um exemplo do aumento da preocupação da comunidade internacional com as chamadas "novas guerras" são as operações de manutenção da paz (ou peacekeeping operations), organizadas pela ONU. Essas missões têm o objetivo de manter a paz e a estabilidade de países arrasados por conflitos civis, como é o caso da missão liderada pelo Brasil no Haiti. Algumas missões têm a meta de observar o cessar-fogo ajustado previamente entre as partes em conflito; outras oferecem assistência aos Estados que estão fazendo a transição de regimes autoritários para democráticos.

Tradicionalmente, procurou-se entender as guerras por meio de explicações históricas, políticas e socioeconômicas. Na obra resenhada, a questão dos recursos econômicos merece tratamento especial. A pobreza e a desigualdade são fatores analisados para melhor compreender os "novos conflitos civis", assim como a busca por recursos como diamantes e petróleo. Os combatentes ou rebeldes que participam das "novas guerras civis" necessitam de recursos econômicos para se sustentarem. Por esse motivo, engajam-se em crimes como seqüestros, extorsões e tráfico de drogas. Na guerra fria, a busca de recursos servia principalmente como meio para atingir um fim definido em termos políticos, como, por exemplo, mudanças de regime ou revoluções socialistas. Na década de 1990, os recursos não são mais um meio para atingir um fim, mas a própria motivação dos conflitos civis. Dessa forma, as razões de muitos conflitos deixaram de ser eminentemente políticas e passaram a incluir motivações econômicas.

Como já enfatizamos uma das principais conclusões da coletânea, escrita basicamente por autores com formação na área de humanidades (Ciência Política, Relações Internacionais, Geografia e História), é a de que as guerras são motivadas por uma multiplicidade de variáveis, tanto econômicas quanto políticas. As considerações formuladas por esses autores procuram reduzir a influência de análises recentes baseadas exclusivamente em explicações quantitativas e econômicas.

Para melhor compreender os propósitos do livro, vale a pena revisar os estudos do economista Paul Collier e de sua colega Anke Hoefler para o Banco Mundial. Usando ferramentas da Economia Analítica, Collier e Hoefler (2001) concluíram que os conflitos eram causados por oportunidades propiciadas pelo comércio de mercadorias primárias (recursos) e que a injustiça não é a causa principal dos conflitos. As categorias que eles utilizam podem ser descritas como "injustiças objetivas" (ou seja, que podem ser mensuradas), sendo que apenas a dominação pela maioria étnica foi considerada importante para explicar as "novas guerras civis". Dessa forma, os autores não encontraram correlação estatística significativa entre os conflitos e os fatores que normalmente são considerados os principais motivos para a injustiça: repressão política e desigualdade econômica (medidas por meio da renda e da propriedade da terra).

Conforme Kuhn (2003), a história das ciências assemelha-se a um pêndulo. Uma teoria emerge e gera uma série de pesquisas empíricas que tentam enquadrar-se em seus modelos conceituais. Posteriormente, outra teoria surge e coloca em xeque os pressupostos do modelo anterior, arrebanhando novamente uma legião de cientistas que procuram pensar segundo os novos moldes. Finalmente, graças à incapacidade de as novas teorias explicarem certos fenômenos da realidade concreta, os pesquisadores retornam aos velhos modelos para tentar preencher as lacunas deixadas pelos desenvolvimentos mais recentes da ciência.

Como aponta I. William Zartman (p. 257-258), no último capítulo da coletânea, a imagem do pêndulo pode ser verificada "idealmente" nos estudos sobre os conflitos internacionais.

Logo após a Segunda Guerra Mundial, os intérpretes dos conflitos internacionais preocupavam-se principalmente com os contenciosos interestatais que surgiam primeiramente nas "cabeças" dos líderes, prestando menos atenção às condições materiais que levavam os governantes a desejarem a guerra. Posteriormente, como a guerra fria trouxe uma paz relativa ao cenário mundial, analistas começaram a acreditar que os conflitos internos eram motivados pelas "forças internacionais", principalmente a interferência das superpotências nos assuntos domésticos dos países. Com a ascensão do nacionalismo anticolonialista, as explicações começaram a girar em torno dos direitos "naturais" e suas conseqüentes negações como as principais causas dos conflitos. Como reação a essas explicações, formulou-se que os conflitos internacionais eram conseqüências da 
pobreza. Apenas recentemente, começou-se a refletir sobre as condições em que a pobreza leva necessariamente ao conflito. Estas pesquisas produziram trabalhos sobre as guerras por recursos econômicos, chegando a ignorar as variáveis políticas, históricas e sociais por completo, como é o caso da obra de Collier e Hoefler citada anteriormente.

Os autores da coletânea procuraram oferecer uma explicação mais equilibrada — combinando elementos subjetivos e objetivos nas suas análises, reequilibrando o "pêndulo" entre as variáveis econômicas e as variáveis políticas, históricas e sociais. Em outras palavras, argumenta-se que enquanto a Economia Analítica lida bem com as variáveis "objetivas" (renda, fragmentação étnica, volume de mercadorias primárias de um país etc.), ela não consegue avaliar propriamente o impacto das variáveis "subjetivas" ou "sociais" (história de um povo, suas crenças e valores).

No capítulo II, Elizabeth Picard busca fazer uma síntese entre a literatura sobre recursos e a discussão sobre as "crenças". A autora argumenta que a caracterização da guerra civil libanesa (1975-1990) como um conflito identitário entre mulçumanos e cristãos pode ser combinada com análises econômicas, que a explicam por meio dos termos "necessidade" e "ganância". Embora o papel dos atores externos fosse importante, um acordo tornou-se possível quando a principal potência regional (a Síria) e a superpotência global (os Estados Unidos) buscaram uma solução pacífica para o conflito. Assim, a autora examina o caso do Líbano à luz das realidades materiais que estavam escondidas debaixo do discurso ideológico, demonstrando que se desenvolveu uma economia de guerra durante o conflito, com grupos e indivíduos beneficiando-se da corrupção existente no país.

Nesse capítulo, discute-se como os três principais recursos do Líbano — drogas, terra e força de trabalho - relacionam-se com a história, a lógica social e os processos políticos que contribuíram para a guerra civil. Por exemplo, o comércio de ópio e de haxixe existia antes da guerra, porém, o conflito deu uma nova dinâmica quantitativa e qualitativa para o narcotráfico. O tráfico de drogas cresceu com a entrada de novos atores no negócio, possibilitando que milícias vivessem de saques nos territórios por elas controlados. Além disso, o período de guerra produziu uma grande leva de imigrantes, que passaram a enviar milhões de dólares para aqueles que permaneciam no país, fornecendo recursos extras para os grupos armados e ampliando o controle das milícias sobre as terras e os bens das pessoas que deixaram a nação.

A guerra civil peruana lembra o caso libanês na medida em que o conflito armado praticamente terminou, mas o movimento guerrilheiro Sendero Luminoso continuou dispondo de uma renda significativa para exercer suas atividades. No capítulo III, Cynthia McClintock mostra como, em meados da década de 1980, o Sendero Luminoso lucrava de 20 a 40 milhões de dólares por ano com o comércio de drogas, tornando o Peru um dos maiores produtores de cocaína do mundo. O Sendero Luminoso usava o dinheiro para pagar salários para seus combatentes e aperfeiçoar sua capacidade militar e organizacional; entre o final dos anos 1980 e o começo de 1990 o movimento controlava aproximadamente $25 \%$ dos municípios do país e contava com cerca de 25 mil militantes.

A autora estabelece a relação entre as noções de injustiça, ideologia e renda do comércio de cocaína para explicar a origem do Sendero Luminoso e o seu crescimento espetacular na década de 1980. O movimento nasceu na década de 1970 nas regiões montanhosas do Sul do Peru. Os agricultores dessa região praticamente não se beneficiaram da reforma agrária promovida pelo governo peruano em 1968. No mesmo período, outras políticas governamentais afetaram os preços e o crédito, e o investimento público declinou, prejudicando ainda mais a já debilitada renda agrícola. Paradoxalmente, o declínio do padrão de vida peruano entre 1971 e 1990 (a renda per capita caiu cerca de $20 \%$ ao ano) foi acompanhado de uma expansão de oportunidades educacionais graças a uma série de reformas do governo. Assim, os filhos dos camponeses, apesar de terem uma maior chance de freqüentar escolas e universidades, frustravam-se ao tentar encontrar boas oportunidades profissionais.

A ideologia marxista-maoísta do Sendero Luminoso fazia sentido no contexto social de desigualdade e pobreza peruano. Assim, o Sendero Luminoso ganhou adeptos nos centros urbanos na medida em que o declínio econômico do Peru acentuava-se na década de 1980. Ao mesmo tempo, o oportunismo, não a ideologia, fez com que o Sendero Luminoso aceitasse o apoio dos produtores de cocaína do sul peruano, que formaram milícias para se protegerem dos programas de erradicação de drogas do governo. Contudo, a autora enfatiza que os recursos serviam basicamente para fins políticos, que o conflito nunca foi movido exclusivamente pela "ganância", um quadro em que o comércio de cocaína tornar-se-ia o único objetivo da luta armada. 
No quarto capítulo, Jimmy Kandesh distingue entre a "ganância" como uma causa da rebelião e como um motivo para ela, argumentando que em Serra Leoa ambos os sentidos foram relevantes para a origem e o caráter do conflito provocado pelos rebeldes da Frente Revolucionária Unida. A "ganância", como causa, refere-se ao impacto social de leis predatórias, pela acumulação financeira por parte da classe política e seu conseqüente papel em impulsionar o colapso do Estado, enquanto a "ganância", como motivo, diz respeito às atividades daqueles que pegaram em armas para saquear os diamantes do país. Assim, o conflito de Serra Leoa caracterizado inicialmente pelo idealismo dos estudantes que pegaram em armas contra o governo corrupto passou a incorporar criminosos e oportunistas, atuantes no país e no exterior, que desejavam lucrar por meio do comércio ilegal de diamantes.

Como em Serra Leoa, no quinto capítulo, Phillipe Le Billon vê relação entre os recursos e a guerra de Angola, também permeada pela degeneração do sistema político, enfraquecimento do Estado, violência estatal acirrada e sectarismo. A intromissão de potências externas após a guerra de independência de Angola, em 1975, transformou uma luta anticolonialista em uma longa batalha: os Estados Unidos, a União Soviética, Cuba, a China, a África do Sul e o Zaire apoiavam a Frente de Libertação Nacional de Angola (FNLA), o Movimento Popular para a Libertação de Angola (MPLA) e a União Nacional para a Total Independência de Angola (UNITA), segundo os interesses estratégicos da guerra fria. Contudo, quando os estrangeiros pararam de apoiar o conflito, no início da década de 1990, a posse de recursos (petróleo pelos governistas da MPLA e diamantes pela UNITA) significativamente influenciou o curso do conflito, prolongando a guerra ao fornecer capital para a continuação da luta e desestimulando o estabelecimento de um acordo de paz.

A possibilidade de obtenção de renda por meio de recursos naturais, como em Serra Leoa, distorceu as instituições e a vida política de Angola, permitindo que as elites tomassem o poder pela força. Elas tinham capital para sustentarem seus exércitos, ao mesmo tempo em que mantinham altos níveis de corrupção, contribuindo para o déficit fiscal e, conseqüentemente, prejudicando a diversificação da economia.

A República Democrática do Congo, ex-Zaire, é o tema do sexto capítulo. Conforme Erik Kennes, os estrangeiros foram os principais desencadeadores dos conflitos armados de 1996-1997 e de 1998-2003, e a briga pela hegemonia regional que provocou a queda do regime de Mobuto Sese Seko foi motivada por objetivos estratégicos e razões econômicas. As diversas facções do movimento rebelde congolês recebiam, em diferentes momentos, o apoio de Ruanda, Uganda, Angola, Zimbábue e Namíbia, sendo que os dois primeiros competiam pelo controle direto e indireto de porções do território do Congo de onde poderiam extrair diamantes. Nesse sentido, Ruanda e Uganda apoiaram a guerra congolesa por "ganância" e pela busca da liderança regional. Como no caso angolano, o conflito do Congo originou-se pela "necessidade", motivando atores que agiam de forma "gananciosa". No entanto, "por mais que a seqüência 'necessidade', 'crença' e 'ganância' forneça uma explicação geral para a guerra civil, a distinção é meramente analítica; no mundo real, os três termos não são seqüenciais, mas cumulativos". Em outras palavras, "a 'necessidade' pode ser a noção que melhor descreve uma situação pré-conflituosa, mas ainda está presente no final do conflito" (p. 141).

O caso colombiano é abordado no sétimo capítulo. Nele, Marc Chernick explora a transformação e o desenvolvimento dos cerca de 50 anos de conflito na Colômbia e a relação entre as questões político-sociais e as exportações de narcóticos, mostrando como os conceitos de "ganância" e "injustiça" ajudam a explicar as origens e a continuação do conflito. $\mathrm{O}$ autor argumenta que o tráfico de drogas passou a jogar um papel importante no conflito a partir de meados da década de 1980, transformando os grupos guerrilheiros. Especialmente as Forças Armadas Revolucionárias da Colômbia (FARCS), que de uma pequena faç̧ão camponesa insurgente passaram a grupo milionário, que dedica parte considerável de seus esforços a atividades criminosas, não à busca de seus ideais socialistas. A ausência do Estado em grandes porções territoriais da Colômbia facilitou o narcotráfico e a expansão do grupo guerrilheiro. Conforme o autor, a experiência colombiana sugere que a injustiça, a ideologia e os fatores internacionais (particularmente o papel dos Estados Unidos na região) explicam as origens e a longa duração da guerra; não apenas a mobilização de recursos e a "ganância".

Em 7 de outubro de 2001, deu-se o início do ataque dos Estados Unidos ao Afeganistão para remover os Talibans do poder, possivelmente enfraquecendo, mas não desmantelando suas conexões com o grupo terrorista Al-Caida. No oitavo capítulo, Paula Newberg descreve que a atual guerra do Afeganistão só pode ser entendida no contexto de três décadas de conflitos internos e externos, que foram provocados pela má administração dos negócios do Estado e pela luta de Kabul contra os rebeldes e os líderes tribais das regiões periféricas do país. Vinte anos antes de o Taliban subir ao poder, os líderes tribais ganharam apoio internacional 
para financiar a guerra contra o seu próprio governo central e contra a União Soviética. A autora argumenta que, como em Serra Leoa e no Congo, o colapso do Estado e as disputas territoriais levaram ao acirramento do conflito no Afeganistão. De fato, parte do conflito originou-se da violenta rejeição da noção de Estado, pois, sem a fiscalização estatal, os lucros obtidos por meio da venda de ópio aumentavam.

Os conflitos internos do país, originados pela fragmentação tribal, étnica e ideológica, tornaram-no um terreno fértil para os "interesses exógenos". Países vizinhos, como o Paquistão e o Irã, potências internacionais, inclusive os Estados Unidos, e movimentos islâmicos transnacionais sustentaram e alimentaram disputas locais, fornecendo dinheiro, equipamento e pessoal. O esforço internacional para desestabilizar a ocupação soviética (1979-1989) criou um novo patamar para a insegurança regional, enfraquecendo política e economicamente os vizinhos do Afeganistão, contribuindo para o aumento da tensão na Ásia Central.

Finalmente, o nono capítulo, escrito por David Malone e Jake Sherman, examina uma série de instrumentos políticos disponíveis para os governos, coalizões multinacionais, organizações internacionais e entidades privadas tentarem lidar com as "novas guerras civis", como, por exemplo: a criação de leis humanitárias, anticrime, antiterroristas e a realização de operações de paz após o término do combate. Conforme os autores, sanções e embargos econômicos ainda são os instrumentos empregados mais freqüentemente, mas medidas para impedir a lavagem de dinheiro, desestabilizar o narcotráfico e minimizar o impacto negativo das atividades ilícitas do setor privado devem ser estimuladas, assim como esforços para combater a corrupção e o crime organizado internacional.

Os autores apontam também para as dificuldades que os formuladores de políticas enfrentam nos países que lucram com os recursos provenientes das regiões em conflito. De fato, é muito difícil combater algumas ações que estimulam os conflitos, como firmas que criam empregos nos países consumidores de recursos ilícitos, normas de segredo bancário e transações monetárias suspeitas. A criação de instrumentos legais para punir o crime de "colarinho-branco" internacional, criando obstáculos para diminuir o lucro obtido por meio da economia de guerra, seria medida para desestimular algumas causas de conflitos movidos por recursos. Outra medida eficaz seria a criação de instituições e regimes internacionais para lidar com os crimes econômicos internacionais de grandes proporções, similares aos que estão sendo desenvolvidos para processar criminosos de guerra, crimes contra a humanidade e de genocídio.

Ao trazer para o debate análises econômicas sem ignorar questões políticas e ideológicas, o livro contribui para a compreensão das "novas" formas de conflito civis. Assim, a obra não é um trabalho com objetivos apenas "acadêmicos". Procura também influenciar a realidade concreta, buscando oferecer alternativas para o término das guerras civis ainda em curso. Tanto é assim que ela foi concebida no Woodrow Wilson Center, um thin-tank que funciona graças a fundos públicos e privados, tendo com o objetivo promover debates e formular políticas públicas de caráter progressista; combatendo, por sua vez, pesquisas sobre a guerra civil formuladas no âmbito do Banco Mundial. Dessa forma, a coletânea é recomendada não apenas para estudantes e pesquisadores de Relações Internacionais, mas também para profissionais, militares e diplomatas, que se preocupam em entender os conflitos para tentar evitá-los.

Gabriel Cepaluni (gcepaluni@yahoo.com.br) é mestre em Relações Internacionais pelo Programa San Tiago Dantas (Universidade Estadual de Campinas - Unicamp), doutorando em Ciência Política pela Universidade de São Paulo (USP) e pesquisador do Centro de Estudos de Cultura Contemporânea (Cedec).

Filipe Mendonça (filipe_relint@yahoo.com.br) mestrando em Relações Internacionais pelo Programa de PósGraduação San Tiago Dantas (Universidade Estadual de Campinas - Unicamp) e pesquisador júnior do Centro de Estudos de Cultura Contemporânea (Cedec).

\section{REFERÊNCIAS BIBLIOGRÁFICAS}

COLliER, P. \& HOEFLER, A. 2000. Greed and Grievance in Civil War. Disponível em: http:// www.worldbank.org/research/conflict/papers/greedgrievance_23oct.pdf. Acesso em : 8.fev.2006.

KUHN, T. S. 2003 [1970]. A estrutura das revoluções cientificas. São Paulo: Perspectiva. 